\title{
Florestan FERnANDES E O CONCEITO dE PATRIMONIALISMO NA COMPREENSÃO DO BRASIL
}

\author{
Aristeu Portela Júnior*
}

Resumo O conceito de patrimonialismo é central nos modos habituais de se interpretar e analisar o Brasil. Sujeito a uma utilização nem sempre rigorosa, objeto de contestações quanto à sua validade analítica, ele precisa ser retomado de modo sistemático para que se possam delinear seus potenciais e suas limitações quanto à compreensão da sociedade brasileira e de sua história. O presente trabalho busca iniciar esse esforço, retomando tanto a conceituação original de Max Weber quanto a análise que Florestan Fernandes realiza do processo de constituição de nossa sociedade nacional. Buscou-se, assim, mostrar que Fernandes, ao apontar para o caráter não monolítico do Estado brasileiro, ao qual se associa, muitas vezes, a noção de patrimonialismo, supera limitações presentes nos modos mais habituais de utilização do conceito, abrindo novas possibilidades analíticas.

Palavras-chave Estado; Florestan Fernandes; Max Weber; patrimonialismo.

\section{Florestan FERnANDES AND the CONCEPT OF PATRIMONIALISM IN THE UNDERSTANDING OF BRAZIL}

Abstract The notion of patrimonialism is central to the habitual ways of interpreting and analyzing Brazilian society. Subject to a use not always accurate, as well as object of disputes concern its analytical validity, this concept needs to be taken in a systematic way so that it can outlines its potential and limitations for the understanding of Brazilian society and its history. The present study attempts to begin this effort by retaking both the original conceptualization of Max Weber and the analysis that Florestan Fernandes performs of the process of constitution of our

Recebido para publicação em 14/05/2012.

Aceito para publicação em 12/11/2012.

* Mestrando do Programa de Pós-Graduação em Sociologia da Universidade Federal de Pernambuco e bolsista de mestrado do CNPq. 
national society. We consider that with such an analysis Fernandes overcomes the limitations present in the more usual use of the concept in the social thinking of Brazil, by pointing to the non-monolithic character of the Brazilian state, which often is associated with the notion of patrimonialism.

Keywords State; Florestan Fernandes; Max Weber; patrimonialism*.

\section{INTRODUÇÃO}

Há determinadas categorias conceituais que se tornaram correntes nos esforços de análise da formação da sociedade brasileira. Conceitos e noções como os de personalismo, patriarcalismo, subdesenvolvimento e dependência fazem parte do acervo que estrutura importantes debates em nossas ciências sociais. É especificamente uma dessas categorias que constitui o objeto de estudo deste trabalho: o conceito weberiano de "patrimonialismo". Pretende-se, aqui, elaborar uma discussão tanto da formulação original do conceito, na obra de Max Weber, quanto de sua utilização no estudo da sociedade brasileira, por meio das análises de Florestan Fernandes acerca do processo de constituição de nosso Estado nacional.

A razão fundamental que leva a enxergar a importância do estudo de tal conceito é a influência que ele exerceu e ainda exerce no pensamento social brasileiro (CAmpante, 2003; Silveira, 2006), alcançando autores das mais diversas matrizes teóricas, entre os quais podem ser citados Oliveira Vianna, Sérgio Buarque de Holanda, Raymundo Faoro, José Murilo de Carvalho, Florestan Fernandes, Maria Sylvia de Carvalho Franco, Elisa Reis e Simon Schwartzman. Como aponta Jessé Souza (2009, p. 63-64), essa noção foi (e continua sendo), para o bem ou para o mal, central para a autocompreensão dos brasileiros, no sentido de auxiliar na cristalização de certa imagem da "brasilidade", fazendo parte do universo semântico por meio do qual nossa sociedade interpretou e interpreta a si mesma, ao longo de seu processo de desenvolvimento.

Nesse cenário, a análise de Florestan Fernandes do processo de Independência do Brasil e da consequente formação do Estado nacional, sobre a qual o trabalho se deterá, ilustra uma maneira de apropriação da noção de patrimonialismo que supera limitações presentes nas análises de outros autores. Daí a importância da retomada de suas reflexões para um uso consciente e crítico desse conceito, ainda mais quando seu estatuto explicativo e compreensivo vem, legitimamente, sendo posto em dúvida (cf. Vianna, 1999; SouzA, 2009, sobretudo a Parte 1).

É plausível levantar a hipótese de que muita da confusão em torno do conceito decorre de uma apreciação pouco atenta de sua formulação original. Obedecendo 
aos mais diversos requisitos (sejam políticos, sejam acadêmicos, etc.), a apropriação da noção de patrimonialismo assumiu diversos sentidos nas ciências sociais brasileiras (cf. VIANNA, 1999, p. 175-180), nem sempre congruentes entre si; algumas mais, outras menos fiéis e atentas aos pressupostos teóricos que ela contém na obra de Weber. Assim, o caminho para uma utilização profícua do conceito deve passar necessariamente pela apreciação crítica de sua formulação na obra do sociólogo alemão. É por esse passo que se inicia o trabalho.

\section{PATRIMONIALISIMO ENQUANTO DOMINAÇÃO TRADICIONAL}

A sociologia política de Weber legou diversas contribuições fundamentais às ciências sociais contemporâneas. De acordo com Bobbio (2003, p. 93), nenhum "dos estudiosos que viveu no século XX contribuiu mais do que Weber para enriquecer o léxico técnico da linguagem política”. E ele continua:

\footnotetext{
É surpreendente o grande número de expressões weberianas que passaram a integrar estavelmente o patrimônio conceptual das ciências sociais. Menciono apenas algumas situadas no campo da teoria política, como poder tradicional ou carismático, poder legal e poder racional, direito formal e direito material, monopólio da força, ética da convicção e ética da responsabilidade, grupo político e grupo hierocrático. Para não falar da "legitimidade", que só depois de Weber se tornou um tema relevante para a teoria política.
}

Entre todas essas contribuições, a que interessa no momento é sua tipologia das formas de dominação, no interior da qual ele conceitua o patrimonialismo. Trata-se de uma classificação assentada nas diferentes naturezas de legitimidade pretendidas pelas associações de dominação, ou seja, nos princípios últimos em que repousa a validez das relações de autoridade, o que significa dizer que uma relação de dominação - enquanto "probabilidade de encontrar obediência para ordens específicas (ou todas) dentro de determinado grupo de pessoas" (WEBER, 2000, p. 139) - se baseia, em alguma medida, em sua aceitação enquanto legítima, por parte dos indivíduos que lhe estão sujeitos, e não apenas (ou principalmente) em motivos de submissão puramente materiais ou afetivos ou racionais referentes a valores.

Buscar despertar e cultivar a crença em sua legitimidade é indispensável à persistência das relações de dominação, no tempo e no espaço. O próprio Estado é definido por Weber como "uma relação de dominação do homem sobre o homem, 
fundada no instrumento da violência legítima" que só pode existir "sob a condição de que os homens dominados se submetam à autoridade continuamente reivindicada pelos dominadores" (WEBER, 2008, p. 57; grifo nosso). Essa legitimidade pode, primordialmente, estar assentada em três princípios distintos, que Weber classifica como "racional", "tradicional" e "carismático".

É sempre importante lembrar que se está aqui tratando de tipos-ideais, ferramentas analíticas, portanto, e não descrições objetivas da realidade. O que uma classificação como a de Weber pode fornecer ao trabalho histórico empírico é a possibilidade de dizer, no caso particular de uma forma de dominação, por exemplo, “o que há nela de 'carismático', de 'carisma hereditário', de 'carisma institucional', de 'patriarcal', de 'burocrático', de 'estamental' etc., ou seja, em quê ela se aproxima de um destes tipos" (WeBER, 2000, p. 141) e, consequentemente, em quê se distancia de outros. Assim, durante todo o tempo em que se tratar das formas de dominação e suas variantes, efetuar-se-á uma análise essencialmente conceitual, de cunho abstrato, portanto, cuja aplicação à realidade empírica não possa se dar de maneira direta.

Feita essa ressalva, a análise pode se voltar para o tipo-ideal de "dominação tradicional", aquele que interessa mais diretamente, aqui, aos propósitos do trabalho. Com ele, Weber designa uma forma de dominação cuja legitimidade está fundamentada na "crença cotidiana na santidade das tradições vigentes desde sempre e na legitimidade daqueles que, em virtude dessas tradições, representam a autoridade" (WEBER, 2000, p. 141). Obedece-se, nessa forma de dominação, não à ordem impessoal, objetiva e legalmente estatuída e aos superiores por ela determinados (o que caracterizaria a dominação racional-legal), nem ao líder carismaticamente qualificado como tal (dominação carismática), mas à pessoa nomeada pela tradição e, em virtude da devoção, aos hábitos costumeiros.

O patrimonialismo consiste em uma forma específica da dominação tradicional, possuindo, portanto, as características apontadas. Propõem-se aqui uma leitura do tema em Weber - com base em Economia e sociedade - que distingue três eixos distintos, mas complementares, de conceituação. Em cada um deles, ao mesmo tempo em que se elaboram as características específicas da "dominação patrimonial”, esse tipo é diferenciado de outras variantes da dominação tradicional. A apresentação vai, portanto, se estruturar com base nesses eixos.

O primeiro se refere à existência e ao estatuto do "quadro administrativo" no seio da associação de dominação. O patrimonialismo se distingue, inicialmente, de formas de dominação tradicional que não possuem um quadro administrativo, como a "gerontocracia" (dominação, dentro de uma associação, exercida pelos 
mais velhos, sendo eles os melhores conhecedores da tradição) e o "patriarcalismo primário" (dominação, dentro de uma associação, exercida por um indivíduo determinado segundo regras fixas de sucessão).

Nesses casos em que está ausente o quadro administrativo, o poder do senhor depende, em grande parte, da vontade de obedecer dos associados, os quais são "companheiros", em virtude da tradição, não "membros" de uma associação, em virtude de estatutos. A ausência do quadro administrativo pessoal - isto é, recrutado a partir de pessoas tradicionalmente ligadas ao senhor, por vínculos de piedade ${ }^{1}$ (o que Weber chama de "recrutamento patrimonial"), como membros do clã, escravos, funcionários domésticos dependentes, clientes, colonos, entre outros (cf. WEBER, 2000, p. 148-150) - determina que os associados enxerguem a dominação como exercida materialmente em favor deles, não existindo apropriação livre desse direito por parte do senhor. É nessa ideia dos associados que se apoia (no tipo puro, evidentemente) o poder dos gerontocratas e dos patriarcas.

Com efeito, a dominação patrimonial nasce a partir de um desenvolvimento específico da dominação patriarcal, quando a comunidade doméstica, que constitui a base do patriarcalismo, descentraliza-se, e certos membros não livres da comunidade são colocados em parcelas com moradia e família próprias e abastecidos com auxílio do "patriarca" ou "príncipe". Embora esse desenvolvimento debilite, em alguma medida, o poder doméstico pleno, estabelece-se uma relação de dependência unilateral que termina por se "estereotipar" nos costumes.

A este caso especial da estrutura da dominação patriarcal: o poder doméstico descentralizado mediante a cessão de terras e eventualmente de utensílios a filhos ou outros dependentes da comunidade doméstica, queremos chamar de dominação patrimonial (WEBER, 2004, p. 238).

O importante a se reter, neste ponto, é o fato de que, dada a descentralização da comunidade doméstica original, quanto mais extensos são os domínios submetidos à autoridade do "príncipe" - e que, no caso mais simples, abrangem "uma fazenda senhorial com um complexo de propriedades territorialmente dependentes e de fazendas de camponeses dependentes pertencentes a estas propriedades" (WEBER, 2004, p. 250) - mais eles exigem uma "administração" organizada e, portanto,

1 "Piedade", no sentido de "respeito filial pela pessoa do pater, intimamente associado à reverência pelo religioso, pelo sagrado, pelo tradicional. A piedade manifesta-se, segundo Weber, pelo sentimento de devoção puramente pessoal ao soberano que caracteriza o patrimonialismo..." (CAmpante, 2003, p. 187). 
uma maior diferenciação das funções. O senhor patrimonial precisa, em outras palavras, de um corpo de funcionários.

De início, o senhor recruta seus funcionários do círculo dos pessoalmente submetidos a ele, por vínculos de piedade. Mas, segundo Weber, dificilmente uma administração pública consegue funcionar apenas com esse tipo de recrutamento. Os senhores políticos eram quase sempre obrigados a recrutar seus funcionários também de forma "extrapatrimonial”, em virtude, sobretudo, do descontentamento dos súditos, ao verem homens não livres alcançarem poder e posições superiores a todos os demais. Como o serviço prestado ao senhor oferecia às pessoas livres vantagens consideráveis, estas se conformavam à submissão ao poder pessoal do senhor. E, "sem dúvida, onde era possível, o senhor insistia na mesma dependência pessoal para os funcionários de proveniência extrapatrimonial e para aqueles recrutados do grupo dos não livres" (WEBER, 2004, 251).

Portanto, é apenas quando surge um quadro administrativo que a dominação tradicional tende ao patrimonialismo. As funções e os serviços no interior desse quadro, inicialmente sujeitas apenas ao arbítrio do senhor, tendem a se "estereotipar” em função da tradição. A estereotipagem e a apropriação monopolizadora dos poderes oficiais pelos detentores cria o tipo "estamental" do patrimonialismo (WEBER, 2004, p. 53). Nessa situação, os poderes de mando da associação e as correspondentes oportunidades de ganho são apropriados por um quadro administrativo definido estamentalmente, isto é, em que o acesso a ele é regulado pelo pertencimento a uma "situação de status" (cf. WEBER, 1982, p. 131), assentada em determinada estimativa de honraria, neste caso, positiva.

O funcionalismo patrimonial, com a progressiva divisão e hierarquização das funções, bem como com a racionalização das tarefas, pode assumir traços burocráticos. No entanto, ao cargo patrimonial falta, sobretudo, a distinção burocrática entre a esfera "privada" e a "oficial” - e aqui se alcança o segundo eixo da conceituação de patrimonialismo.

Na dominação patrimonial, a administração é tratada como assunto puramente pessoal do senhor, e a propriedade e o exercício de seu poder, como partes de seu patrimônio pessoal.

A dominação patrimonial e especialmente a patrimonial-estamental trata, no caso do tipo puro, igualmente todos os poderes de mando e direitos senhoriais econômicos e as oportunidades econômicas privadas apropriadas. [...] Para nossa terminologia, o decisivo é o fato de que os direitos senhoriais e as corresponden- 
tes oportunidades, de todas as espécies, são em princípio tratados da mesma maneira que as oportunidades privadas (WEBER, 2000, p. 155, grifos no original).

A forma como o senhor exerce o poder é, portanto, objeto de seu livre-arbítrio - o qual, no entanto, é circunscrito aos limites impostos pela tradição. É justamente nesse binômio arbítrio/tradição que se funda a diferença entre o patrimonialismo e outra variante da dominação tradicional: o "sultanismo". A diferença é fluida, mas existente: sendo o patrimonialismo "toda dominação que, originalmente orientada pela tradição, se exerce em virtude de pleno direito pessoal”, o sultanismo se caracteriza por uma desvinculação em um grau ainda maior da tradição, desenvolvendo-se nele ao extremo a esfera do arbítrio do senhor (WEBER, 2000, p. 151-152).

Tanto no patrimonialismo quanto no sultanismo, no entanto, os "companheiros" se tornam "súditos", e o direito do senhor, interpretado nas outras formas de dominação tradicional como direito preeminente dos associados, converte-se em seu direito próprio, "apropriado por ele da mesma forma (em princípio) que um objeto possuído de natureza qualquer, valorizável [...], em princípio, como outra oportunidade econômica qualquer" (WEBER, 2000, p. 151). Além dessas características, os dois tipos se distinguem ainda do patriarcalismo e da gerontocracia pela existência de um quadro administrativo pessoal.

No interior desse quadro, como apontado, é o parecer puramente pessoal do senhor que decide sobre a delimitação das "competências" de seus funcionários - sobretudo no início, quando ainda não se trata de funções tradicionalmente estereotipadas. O funcionário, aqui, é “ocasional”, isto é, de incumbência circunscrita pela finalidade objetiva concreta de sua tarefa e selecionado segundo a confiança pessoal, não segundo a qualificação objetiva. Tal situação consiste no terceiro eixo de definição do patrimonialismo.

Quando a administração de grandes formações políticas está patrimonialmente organizada, toda tentativa de determinar "competências" acaba [...] afogada numa maré de títulos oficiais com sentido que varia quase totalmente por livre-arbítrio (WEBER, 2004, p. 254).

Essas características permitem a Weber traçar uma diferenciação no seio da dominação patrimonial, a qual pode tanto se aproximar mais de um esquema tradicionalmente "estereotipado" da distribuição de cargos, no seio do quadro administrativo, ou mais de um esquema "arbitrário" por parte do senhor (nova- 
mente o eixo tradição/arbítrio como central ao patrimonialismo). No primeiro caso, com o progresso da apropriação estamental dos cargos, o poder senhorial "desintegra-se" para formar uma constelação de direitos senhoriais de determinados indivíduos, nos quais o senhor não pode tocar sem provocar conflitos (e cujo desenvolvimento, como será apontado, pode desembocar no feudalismo). No segundo caso, nas áreas em que não se realizou essa apropriação de cargos, predomina a arbitrariedade em princípio totalmente livre do senhor, o qual delega, sem restrições, tarefas e posições a favoritos pessoais.

Em ambos os casos, no entanto - na dominação patrimonial em geral -, estão ausentes as normas e os regulamentos burocráticos; falta ao cargo fundamentado em relações puramente pessoais a ideia do dever objetivo. A posição do funcionário patrimonial, em oposição à do burocrata, é produto de sua relação puramente pessoal de submissão ao senhor. A fidelidade ao cargo por parte do funcionário patrimonial não é uma fidelidade do servidor perante tarefas objetivas, delimitadas por regras racionalmente estabelecidas, mas, sim, uma fidelidade de "criado", o que constitui uma parte integrante de seu dever de piedade e fidelidade ao senhor.

Faltam [na dominação patrimonial] a ordem objetiva e a objetividade encaminhada a fins impessoais da vida estatal burocrática. O cargo e o exercício do poder público estão a serviço da pessoa do senhor, por um lado, e do funcionário agraciado com o cargo, por outro, e não de tarefas “objetivas” (WEBER, 2004, p. 255).

A distinção entre o funcionalismo patrimonial e o burocrático permite ainda diferenciar, no pensamento de Weber, a dominação patrimonial do feudalismo - outra variante de dominação tradicional. Fundamentalmente, é da fase do "militarismo cavaleiroso da economia patrimonial extensa" que nascem as relações de fidelidade, entre senhores e vassalos, características do feudalismo, e as quais são fixadas em contrato.

Em contraste com a ampla esfera de arbitrariedade e com a correspondente baixa estabilidade das posições de poder do patrimonialismo puro, encontra-se a estrutura das relações feudais. O feudalismo é um "caso-limite" da estrutura patrimonial, no sentido da estereotipagem e fixação das relações entre os senhores e os vassalos (WEBER, 2004, p. 288, grifos no original).

Em oposição à dominação patrimonial - fundado na existência de duas esferas - a da vinculação entre senhor e funcionários por meio da tradição e dos 
direitos apropriados, por um lado, e a do livre-arbítrio do senhor, por outro - o feudalismo assume um aspecto mais "constitucional”, no sentido de que se funda em um contrato bilateral entre senhor e vassalos; um contrato que implica direitos e deveres de ambos os lados, inclusive com restrições da autoridade do senhor sobre os subvassalos (isto é, os vassalos de seus vassalos).

No feudalismo fixam-se, portanto, em alguma medida (e ao contrário da relação patrimonialista), a natureza e a distribuição dos poderes senhoriais. Contudo, não se trata de um Estado burocrático, pois estão ausentes tanto a regulamentação geral quanto a classificação racional das competências específicas e a delimitação dos deveres administrativos circunscritos.

O feudalismo também se distingue da burocracia e da dominação patrimonial por seu caráter necessariamente estamental. A burocracia e o funcionalismo patrimonial se fundamentam em um "nivelamento social", no sentido de que, em seu tipo puro, ou apenas importam as qualificações objetivas de uma pessoa em determinada área (burocracia) ou importam as qualificações puramente pessoais (patrimonialismo), abstraindo-se as diferenças estamentais - independentemente da circunstância de as camadas de funcionários burocráticos e patrimoniais tenderem a se tornar portadoras de determinada "honra" social, com a consequente formação de estamentos.

Contudo, o feudalismo, no sentido definido por Weber, apresenta uma necessária orientação estamental e assume cada vez mais esse caráter. $O$ vassalo tinha que ser um homem livre, isto é, não sujeito ao poder patrimonial de um senhor. Portanto, dado que se fundamenta em enfáticos conceitos de honra especificamente estamentais, enquanto fundamento das relações de fidelidade, a relação feudal plenamente desenvolvida somente pode se realizar em uma camada senhorial. É por isso que Weber (2004, p. 302) apresenta o feudalismo como o caso-limite do "patrimonialismo estamental".

Esses três eixos permitem sistematizar melhor a conceituação de "patrimonialismo" em Weber. Dado que a apropriação desse conceito no pensamento social brasileiro obedece a diversas aproximações e distanciamentos com relação à formulação original - "quando se analisam as correntes de pensamento que versaram sobre tal enfoque [o patrimonialismo no Brasil] verifica-se um desdobramento deste conceito, que frequentemente escapa a sua vertente genética weberiana” (Silveira, 2006, p. 1) -, essa sistematização pode consistir em um caminho profícuo para a interrogação acerca dos modos que ele assume no estudo da sociedade brasileira. 


\section{ESTADO NACIONAL BRASILEIRO E O CONFLITO COM A DOMINAÇÃO PATRIMONIAL}

É uma tarefa escorregadia a de tentar sistematizar o uso do conceito de patrimonialismo nos trabalhos de Florestan Fernandes. Não só essa categoria é uma entre outras influências weberianas em seu pensamento (cf. CoHN, 1986; IANNI, 2004), como o fato de este ser marcado por aquilo que Gabriel Cohn (1987) chamou de "ecletismo bem temperado" torna no mínimo problemática qualquer tentativa de apresentar as referidas influências sem considerar outras, oriundas de tradições teóricas distintas.

Dada essa peculiaridade de sua produção intelectual, a opção tomada neste trabalho, além de limitar-se à sua sociologia histórica, foi a de abster-se da construção de "genealogias" de conceitos e dedicar-se à apresentação do modo como uma categoria explicitamente calcada na obra de Weber (caso da noção de "patrimonialismo") é mobilizada na reconstrução de processos históricos cruciais para a constituição do "Brasil moderno", que levaram à superação da situação colonial e à conformação da sociedade nacional. Evidentemente limitada, a exposição a seguir intenciona mostrar as adaptações a que Fernandes submeteu o conceito weberiano original, em virtude das singularidades do processo histórico brasileiro de formação de uma sociedade nacional.

O ponto de partida para tal análise não poderia ser outro senão o processo de colonização. Fernandes se insere em uma longa tradição de estudos que, sob diversas perspectivas, enxerga como cruciais as instituições e os padrões de relações sociais que foram trazidos de Portugal para o Brasil - embora sua ênfase, nesse sentido, seja certamente menor que a de autores como Oliveira Vianna, Gilberto Freyre e mesmo Sérgio Buarque de Holanda e Raymundo Faoro.

De todo modo, o sociólogo paulista afirma que, com a colonização, os portugueses transplantaram, para cá, a ordem social que tinha vigência em Portugal, na época dos descobrimentos e da conquista. Houve, portanto, uma tentativa deliberada de "preservação e de adaptação de todo um corpo de instituições e de padrões organizatórios-chaves, com vistas à criação de um 'novo Portugal' [...] que deveria emergir das condições sociais de vida de uma colônia de exploração" (FERnANDES, 2010, p. 64).

Central, portanto, para a compreensão desses primeiros momentos do que viria a ser a sociedade brasileira é a própria caracterização da "ordem social que tinha vigência em Portugal”, bem como do Estado português no interior desta, na medida em que foi ele o principal agente do processo de colonização. É na 
caracterização do Estado português, à época, que Fernandes (2010, p. 67) adentra explicitamente no terreno conceitual que aqui interessa:

[S]e tomarmos como ponto de referência teórica as conclusões de M. Weber em seu estudo comparado do patrimonialismo e do feudalismo, o império colonial português da época dos descobrimentos, da expansão marítima e da conquista organizava-se como um complexo Estado patrimonial (FERNANDES, 2010, p. 67).

Essa citação é ilustrativa do modo como o conceito de "patrimonialismo" vai ser utilizado pelo autor em suas análises. Trata-se, na maior parte dos casos, de um uso quase que exclusivamente "descritivo", isto é, que dispensa elaborações mais detalhadas de sua significação conceitual. O termo jamais é esmiuçado, nesse sentido, talvez em função de o autor, nesse quesito, vincular-se diretamente à obra de Weber (no que a citação também é ilustrativa); ou talvez seja devido à própria situação histórica analisada, que permite um uso mais "genérico" do termo, na medida em que se tratava de uma "simples" transposição de estruturas já constituídas em Portugal. Quando da complexificação dessa realidade, o uso do conceito por Fernandes será diferente, como será abordado.

Em se tratando do estudo desse momento da história brasileira, pode-se, em virtude da análise realizada de Weber, sugerir a leitura de que, por "patrimonial”, Fernandes está aqui compreendendo um Estado não só composto por um quadro administrativo pessoal do rei, como também um Estado cujas funções e cujos benefícios são apropriados de forma privada pelo rei e seus quadros. Essa característica do Estado português, nesse momento específico da história brasileira, é significativa, pois indica como o processo de colonização vai se desenvolver, no sentido de beneficiar os interesses dos setores ligados à Coroa portuguesa, por meio de "relações patrimoniais".

A transferência da ordem estamental existente em Portugal para o Brasil deveria obedecer aos imperativos dessas relações, o que se evidencia no processo de concessão de sesmarias, cujo fito principal era demarcar, no vasto território "virgem" do que viria a ser o Brasil, estruturas de poder que favoreciam unicamente os agentes da Coroa e estruturas que não podiam ser destruídas, na medida em que serviam de base ao fortalecimento do próprio Estado patrimonial. O latifúndio não foi, portanto, a única consequência dessa concentração da propriedade da terra; com ela, a massa da população livre foi excluída do controle do poder local e do direito de ter vínculos diretos com o Estado. A terra, portanto, nesse momento, erigiu-se "na base material da transferência e da perpetuação de uma arraigada 
estrutura de privilégios e da própria dominação patrimonialista” (FERNANDES, 2010, p. 69).

Com os latifúndios e a criação das "grandes lavouras", efetua-se um alto grau de concentração estamental do poder, da riqueza e do prestígio (cf. FERnANDEs, 2008b, p. 98-99). Apenas um número significativamente restrito de chefes das "grandes famílias" vai poder exercer alguma influência nos rumos históricos do país - ainda que limitada em virtude dos controles externos da metrópole e de seus representantes.

As consequências dessa concentração se fazem sentir em praticamente toda a evolução política posterior do Brasil, do modo como Fernandes a interpreta. Foi, com efeito, graças a essa composição estrutural (cujas características são acentuadas no período imperial) que a maior parte da população brasileira adulta acabou por não ter participação direta na vida política ou ter acesso a ela apenas para exercer atividades subordinadas aos interesses das camadas dominantes. Formaram-se, assim, duas orientações de comportamento, que eram sancionadas pela tradição e reforçadas por uma longa prática: de um lado, nas camadas populares, a de alheamento e de desinteresse pela vida política; de outro, nas camadas dominantes, a de que o exercício do poder político fazia parte dos privilégios inalienáveis dos setores “esclarecidos” ou "responsáveis" da nação (Fernandes, 2008b, p. 99).

Uns não identificavam em nenhum ponto os seus interesses sociais com os destinos do Estado; outros identificavam-nos demais... Essa foi a herança recebida pela República. O que foi feito dela? O que não poderia deixar de ser feito. $\mathrm{O}$ Estado assumiu de vez o belo aspecto das coisas dúplices: "Por fora, bela viola; por dentro, pão bolorento”. Ele possuía uma organização, do ponto de vista jurídico; outra, que era a sua antípoda, do ponto de vista prático (Fernandes, 2008b, p. 99).

A dominação patrimonial, entendida nesses termos, manifestava-se, em sua plenitude, no âmbito do que Fernandes chama de "domínio", isto é, o conjunto das instituições e relações sociais que giravam em torno da "grande lavoura". Na época colonial, esses "domínios senhoriais" eram relativamente autônomos entre si, além de indiferentes uns aos outros e ocasionalmente beligerantes, o que consiste em uma evidência de que, a despeito das relações patrimonialistas serem um fator comum a todos, não havia mecanismos sociais que estimulassem a solidariedade de interesses entre as camadas senhoriais. A dominação patrimonialista se dispersa em "ilhas" pelo Brasil. Apenas com a supressão do estatuto 
colonial e a lenta conformação de uma sociedade nacional, a esfera do "domínio" passará por transformações que colocarão a dominação patrimonial em outro nível de influência.

Enquanto perdurou o estatuto colonial, o poder do senhor ficou confinado a unidades sociais estreitas, isoladas e fechadas. A dominação senhorial traduzia um estilo de pensamento e de ação, mas não integrava a visão de mundo e a organização do poder dos seus agentes, como e enquanto membros de estamentos dominantes. Ao romper-se aquele estatuto e, especialmente, ao projetar-se o senhor nos papéis relacionados com a implantação de um Estado nacional, sua capacidade de entender a significação política dos privilégios sociais comuns aumentou. Ao mesmo tempo, descobriu que a proteção e a expansão dos mesmos privilégios dependiam da extensão da dominação senhorial aos outros planos da vida social, principalmente àqueles em que qualquer senhor se tornava um aliado natural de outro senhor (FERNANDEs, 2006, p. 60-61).

Assim, é sob o nascente Estado nacional, cujas instituições oficiais controlam, que os estamentos dominantes passam a construir os fundamentos de sua solidariedade de interesses e propósitos. E, nesse movimento, utilizam-se dos mecanismos estatais para perpetuar as condições socioeconômicas que salvaguardam seus privilégios. O Estado assume uma configuração de "amálgama”, como bem coloca Fernandes (2006, p. 90-91): liberal em seus fundamentos formais (pois a absorção do liberalismo era requisito para a associação livre, embora dependente, do Brasil às nações que controlavam o mercado externo e para as estruturas internacionais de poder); na prática ele era instrumento da dominação patrimonialista. Ao mesmo tempo em que servia como âmbito de integração legal (portanto, racional) da sociedade, tratava-se de um Estado organizado para servir aos propósitos econômicos, aos interesses sociais e aos desígnios políticos dos estamentos senhoriais.

Assim configurado, o Estado fornecia um novo âmbito de funcionamento para a dominação patrimonial. Esta deixava de se restringir à esfera do "domínio senhorial" e passava a influenciar os destinos da "sociedade nacional", pois o próprio âmbito de atuação dos senhores rurais se expande. A dominação patrimonial, assim, converte-se em dominação estamental propriamente dita. É o que Fernandes (2006, p. 80) chama de "burocratização da dominação patrimonialista".

Evidencia-se, aqui, uma nítida evolução no modo como o autor trabalha com o conceito de patrimonialismo. Embora seu uso continue possuindo um caráter mais "descritivo", como destacado, nos momentos em que a análise se volta para 
as contradições da constituição de uma sociedade nacional no pós-Independência, Fernandes parece perceber que o conceito precisa ser mais bem qualificado.

Não se trata mais, nesse momento, de compreender um padrão de relações sociais que foi transplantado de Portugal, mas sim as transformações que ele sofre quando se insere em uma nova conjuntura nacional e internacional. Por isso, "patrimonialismo" e "dominação patrimonial” são categorias que não serão mais utilizadas, do mesmo modo, para qualificar as relações do âmbito do "domínio" e aquelas que se referem à sociedade nacional. Fernandes vai se valer agora de uma variação dessas categorias, ainda calcada em Weber: a da "dominação patrimonial-estamental".

É importante sublinhar que o uso por Fernandes de tal conceito, segundo a leitura aqui feita, destoa fundamentalmente do uso daquele que talvez seja seu mais famoso divulgador no Brasil: Raymundo Faoro. Para este, a "realidade histórica brasileira demonstrou [...] a persistência secular da estrutura patrimonial" (FAORO, 2008, p. 822). Tal estrutura se caracteriza pelo domínio irrestrito de um estamento burocrático, uma camada social que exerce o poder político em causa própria e cuja principal característica é, exatamente, "a de dominar a máquina política e a administrativa do país, através da qual fazia derivar seus benefícios de poder, prestígio e riqueza" (SCHWARTZMAn, 2003, p. 209). O instrumento de poder desse estamento é justamente o controle patrimonialista do Estado - podendo-se compreender "patrimonial”, aqui, segundo a leitura fundamentada na descrição e análise histórica contida em Os donos do poder, a partir principalmente dos dois primeiros eixos de definição do conceito em Weber, que já apontamos.

Mas o ponto central da argumentação de Faoro, para os propósitos deste trabalho, é o fato de a dominação patrimonial ter se mantido praticamente inalterada, monolítica, por um período da história brasileira que vai desde a sua transplantação de terras portuguesas até, pelo menos, a ditadura do Estado Novo. Como o próprio autor coloca, referindo-se ao Estado patrimonial: “De Dom João I a Getúlio Vargas, numa viagem de seis séculos, uma estrutura político-social resistiu a todas as transformações fundamentais, aos desafios mais profundos, à travessia do oceano largo" (FAORO, 2008, p. 819), o que significa dizer que o estamento burocrático continuou a controlar o Estado brasileiro segundo interesses particularistas, a divorciá-lo das demandas da nação, a estabelecer um controle político sobre a economia, mesmo atuando "debaixo de uma ordem nominalmente racional-burocrática” (FAORO, 1993, p. 16).

A progressiva conformação de uma sociedade nacional, moderna, teria surtido pouco efeito no sentido de alterar essa realidade fundamental. "A pressão da 
ideologia liberal e democrática não quebrou, nem diluiu, nem desfez o patronato político sobre a nação, impenetrável ao poder majoritário, mesmo na transação aristocrático-plebeia do elitismo moderno" (FAORO, 2008, p. 836-837). Em um trecho repleto de construções metafóricas, o autor parece resumir essa perspectiva:

A máquina estatal resistiu a todas as setas, a todas as investidas da voluptuosidade das índias, ao contato de um desafio novo - manteve-se portuguesa, hipocritamente casta, duramente administrativa, aristocraticamente superior. Em lugar da renovação, o abraço lusitano produziu uma social enormity, segundo a qual velhos quadros e instituições anacrônicas frustram o florescimento do mundo virgem. Deitou-se remendo de pano novo em vestido velho, vinho novo em odres velhos, sem que o vestido se rompesse nem o odre rebentasse (FAORO, 2008, p. 837).

A visão de Florestan Fernandes parece um pouco mais sutil. Para ele, a burocratização da dominação patrimonialista, longe de conduzir a um mero predomínio desta em todos os âmbitos do Estado, cria uma espécie de "dualidade estrutural" entre, de um lado, as formas de dominação consagradas pela tradição e, de outro lado, as formas de poder criadas pela ordem legal. As relações patrimonialistas continuaram a ter plena vigência no nível do domínio senhorial propriamente dito (ou seja, na organização da economia escravista e nas estruturas sociais que lhe serviam de base), bem como nas relações sujeitas ao prestígio pessoal dos senhores e ao poder de mando das grandes parentelas; no entanto, a organização do "poder central" foi colocada em um plano independente e superior, no qual a dominação patrimonialista se fazia sentir apenas de maneira indireta e condicionante. Essa configuração, portanto,

compelia as camadas senhoriais a organizar sua dominação especificamente política através da ordem legal, ao mesmo tempo em que conferia ao "poder central" meios para impor-se e para superar, gradualmente, o impacto sufocante do patrimonialismo (FERNANDES, 2006, p. 56).

Os estamentos dominantes possuíam, assim, duas esferas dentro das quais se exerciam suas probabilidades de poder: o nível do "domínio" e o nível da "nação". E, embora eles nem sempre conflitassem, é evidente que, nessa alteração, para efeitos políticos, o domínio deixava de ser visto em si mesmo: toda e qualquer ação, de maior ou menor importância para a coletividade, voltava-se de um modo ou 
de outro para a totalidade do país e afetava seu presente e seu futuro. À medida que progride a burocratização da dominação patrimonialista e que se consolida o Estado nacional emergente, domínio e nação tenderão a harmonizar-se como polos diferenciados, distantes, mas interdependentes.

Embora daí resultasse que a burocratização do poder estamental e a integração nacional fossem fenômenos equivalentes, o que acarretava a elevação do privatismo em princípio de ordenação societária, nem todos os efeitos dessa vinculação seriam "particularistas". Ao contrário, essa conexão é que conferiu aos senhores rurais condições para converterem a satisfação de seus objetivos privados comuns em fator político de interesse geral. Assim, a situação nacional adquiria um significado político que transcendia ao privatismo (FERNANDES, 2006, p. 8o-81, grifos no original).

O patrimonialismo permanecia atuante, sem dúvida, mas, com a progressiva constituição dos caracteres autônomos típicos de uma sociedade nacional, os estamentos dominantes, únicos segmentos de expressão histórica dentro do país, mobilizam-se com o fito consciente e expresso de "organizar a sociedade nacional" e o fazem de maneira a identificar seus interesses econômicos, sociais e políticos com a "riqueza", a "independência" e a "prosperidade" da nação.

Evidentemente que o que estava em questão era a adaptação das elites das camadas dominantes ao que Fernandes chama de requisitos morais e sociais da ordem social competitiva, que então começa a se expandir, mas se trata de um processo extremamente contraditório, em que as estruturas e instituições do "antigo regime" - isto é, para o autor, a ordem escravocrata e senhorial - persistem e influenciam o desenvolvimento dos novos padrões societários (FERNANDEs, 2008a, p. 302-303). As relações patrimonialistas consistem em uma dessas "persistências". Como bem coloca Sérgio Buarque de Holanda - considerado um dos primeiros a utilizar, a partir de Weber, o termo "patrimonial” na análise do Brasil (cf. Silveira, 2006) $)^{2}$-, o fato de os detentores das posições públicas de responsabilidade, no

2 E aqui cabe uma observação no mínimo curiosa. Raymundo Faoro afirma que o historiador paulista mencionado pode ser considerado o introdutor da palavra "patrimonial" nas análises sociais brasileiras, mas não do conceito de "patrimonialismo". Na interpretação de Faoro, Sérgio Buarque não seguiria à risca as ideias de Weber, pois considera que o Estado é a continuação do poder do pater-familias na política, quando para Weber o patrimonialismo implicaria necessariamente a superação do patriarcalismo. O introdutor consequente do conceito de patrimonialismo seria, ao invés, ele próprio, Faoro: "Não há dúvida, portanto, que não o termo 'patrimonial', mas a análise do Estado brasileiro sob o prisma do patrimonialismo, começa com Os donos do poder" (FAORO, 1993, p. 18). 
período em que deslancha no país o processo de urbanização (com a formação de necessidades de trabalhos inexistentes até então), terem sido predominantemente formados no ambiente familiar patriarcal, dificultava que eles compreendessem a distinção fundamental entre os domínios do privado e do público e, ao assumirem as novas funções urbanas, incluindo aí a gestão política, teriam se apropriado delas como assuntos de interesse particular.

"Assim, eles se caracterizam justamente pelo que separa o funcionário 'patrimonial' do puro burocrata conforme a definição de Max Weber" (HolandA, 2009, p. 145-146). Tudo está relacionado a interesses pessoais do funcionário - funções, empregos, benefícios, escolha de empregados - e não a interesses objetivos, como aconteceria, na perspectiva de Holanda, no verdadeiro Estado burocrático, em que prevaleceriam a especialização das funções e o esforço para se assegurarem garantias jurídicas aos cidadãos. Dessa forma, pode-se dizer que, no Brasil, "só excepcionalmente tivemos um sistema administrativo e um corpo de funcionários puramente dedicados a interesses objetivos e fundados nesses interesses" (HolandA, 2009, p. 146).

Embora não se possa, neste momento, dedicar tempo para traçar as aproximações e diferenças entre as perspectivas de Florestan Fernandes e de Sérgio Buarque de Holanda, bem como a de Raymundo Faoro, quanto à aplicação do conceito de patrimonialismo na compreensão da sociedade brasileira, o que a análise anterior permite observar é que Fernandes se mantém fiel à conceituação original de "patrimonialismo" na obra de Weber, ainda que, como é característico de sua produção, se adapte o conceito para melhor compreender e explicar a realidade brasileira. Ao captar a dimensão da burocratização da dominação patrimonialista, que aponta para o caráter não monolítico do Estado brasileiro, ele supera limitações contidas na leitura dominante do conceito (cf. SouzA, 2009, p. 84), que subsumem o Estado à sua dimensão patrimonial, praticamente demonizando-o.

\section{CONSIDERAÇÕES FINAIS}

Evidentemente que não havia a pretensão de realizar neste espaço uma análise exaustiva da obra dos dois autores em pauta; tratou-se, antes, de comentários sobre aspectos específicos de suas formulações. Pode-se ainda dizer que as discussões relativas ao patrimonialismo não se esgotam no que foi abordado aqui.

Nos termos da obra de Weber, para uma análise mais completa, seria ainda necessário apontar as relações da dominação patrimonial com a esfera da economia. Mais especificamente, o sociólogo alemão parece preocupado com os aspectos do 
patrimonialismo que inibem a economia racional, como a ausência de estatutos formalmente racionais e com duração confiável, bem como de um quadro de funcionários com qualificação profissional formal (cf. WEBER, 2000, p. 158).

Quanto à discussão do patrimonialismo em Florestan Fernandes e no pensamento social brasileiro, em geral, é preciso apontar que ela não se limita a análises de períodos específicos do passado histórico. Via de regra, as relações patrimonialistas são vistas como um dos fatores que, no presente, obstaculizam a conformação de uma ordem social democrática no Brasil - como o próprio Fernandes argumentaria em seus escritos para a imprensa no final da década de 1980. Passado e presente nunca estão completamente separados nessas análises.

Traçar um caminho que vai da possibilidade heurística do conceito para a compreensão do passado brasileiro até chegar ao presente, tendo por fundo as formulações originais de Weber, parece uma via profícua para se construir uma compreensão tanto das potencialidades quanto das limitações do conceito para a compreensão da sociedade brasileira, a fim de apontar tanto aqueles processos sociais que essa categoria permite desvendar quanto aquilo que tal perspectiva tem mantido na sombra das análises; mais especificamente, para apropriar-se das dimensões críticas que o conceito desvenda acerca da formação social brasileira na medida em que põe em foco não só a concentração de poder político nas mãos de determinadas camadas sociais, como também a condução desse poder segundo interesses particularistas - e também para, na esteira do que argumenta Vianna (1999), questionar acerca dos limites envoltos no uso tradicional do conceito, que tende a restringir a análise (e crítica) das relações patrimoniais ao âmbito do Estado, deixando em segundo plano as manifestações da dominação patrimonial que se realizam no âmbito social mais geral.

Nesse sentido, o estudo da obra de Florestan Fernandes, como se espera ter mostrado, consiste em uma via possível de construção de novas possibilidades analíticas da noção de "patrimonialismo" e, assim, de elaboração de novas (auto) compreensões da sociedade brasileira e sua história.

\section{REFERÊNCIAS BIBLIOGRÁFICAS}

Bоввіо, Norberto. Max Weber e os clássicos. In: BobBio, Norberto; SAnTILLÁn, José Fernández (Org.). Norberto Bobbio: o filósofo e a política. Rio de Janeiro: Contraponto, 2003. p. 93-116.

CAmpante, Rubens Goyatá. O patrimonialismo em Faoro e Weber e a sociologia brasileira. Dados, Rio de Janeiro, v. 46, n. 1, p. 153-193, 2003. 
Cohn, Gabriel. Padrões e dilemas: o pensamento de Florestan Fernandes. In: Moraes, Reginaldo et al. (Org.). Inteligência brasileira. São Paulo: Brasiliense, 1986. p. 125-148. O ecletismo bem temperado. In: D’Incao, Maria Ângela (Org.). O saber militante. Rio de Janeiro: Paz e Terra, 1987.

FAOrO, Raymundo. A aventura liberal numa ordem patrimonialista. Revista USP, n. 17, p. 14-29, 1993.

. Os donos do poder. São Paulo: Globo, 2008.

Fernandes, Florestan. A revolução burguesa no Brasil. São Paulo: Globo, 2006.

. A integração do negro na sociedade de classes. v. 1: O legado da "raça branca". São Paulo: Globo, 2008a.

Existe uma crise da democracia no Brasil? In: Fernandes, Florestan.

Mudanças sociais no Brasil. São Paulo: Global, 2008b. p. 93-113.

A sociedade escravista no Brasil. In: Fernandes, Florestan. Circuito fechado.

São Paulo: Globo, 2010. p. 37-95.

Holanda, Sérgio Buarque. Raízes do Brasil. São Paulo: Companhia das Letras, 2009.

IANNI, Octavio. Florestan Fernandes e a formação da sociologia brasileira. In: IANNI, Octavio.

Pensamento social no Brasil. Bauru, SP: Edusc, 2004. p. 307-348.

Schwartzman, Simon. Atualidade de Raymundo Faoro. Dados, Rio de Janeiro, v. 46, n. 2. p. 207-213, 2003.

Silveira, Daniel Barile da. Patrimonialismo e a formação do Estado Brasileiro: uma releitura do pensamento de Sergio Buarque de Holanda, Raymundo Faoro e Oliveira Vianna. Conselho Nacional de Pós-Graduação em Direito, v. 1, p. 203-223, 2006. Disponível em: <http://www.egov.ufsc.br/portal/sites/default/files/anexos/259982600o-1-PB.htm>. Acesso em: 5 dez 2011.

SouzA, Jessé. Ralé brasileira: quem é e como vive. Belo Horizonte: Editora UFMG, 2009. Vianna, Luiz Werneck. Weber e a interpretação do Brasil. In: Souza, Jessé (Org.). $O$ malandro e o protestante. Brasília: Editora UnB, 1999. p. 173-193.

Weber, Max. Classe, estamento, partido. In: Mills, C. Wright; Gerth, H. H. (Org.). Ensaios de Sociologia de Max Weber. Rio de Janeiro: LTC, 1982. p. 126-137.

. Economia e sociedade. v. 1. Brasília: Editora UnB, 2000.

. Economia e sociedade. v. 2. Brasília: Editora UnB, 2004.

A política como vocação. In: Weber, Max. Ciência e política. Duas vocações.

São Paulo: Cultrix, 2008. p. 55-124. 
